Pacific Journal of Mathematics

A CONVERGENCE THEOREM WITH BOUNDARY 


\section{A CONVERGENCE THEOREM WITH BOUNDARY}

\section{S. SIMONS}

This paper contains a bounded-convergence type theorem that depends on the fact that certain functions attain their suprema. Among the applications discussed are Rainwater's theorem and two technical results, one used in the proof of the Choquet-Bishop-deLeeuw theorem and the other in the proof of Krein's Theorem.

The contents of this paper and the two following it were suggested by some results and techniques of R. C. James and J. D. Pryce.

The main result of this paper is Lemma 2. See [1], Lemma 2 and [5], Lemma 4 for the source of the idea. We deduce from Lemma 2 a one-sided convergence theorem (Theorem 3) and a two-sided convergence theorem (Theorem 8).

Corollary 4 is a strict generalization of the following result: if $\left\{f_{n}\right\}_{n \geqq 1}$ is a uniformly bounded sequence of concave uppersemicontinuous functions on a compact subset $X$ of a real Hausdorff locally convex space and $\lim \inf _{n \rightarrow \infty} f_{n}(x) \geqq 0$ for each extreme point $x$ of $X$ then $\lim \inf _{n \rightarrow \infty} f_{n}(x) \geqq 0$ for each $x \in X$. (See [4], Lemma 4.3, p. 28.) The latter result is used in one proof of the Choquet-Bishop-deLeeuw theorem. (For an alternative approach see [7], Theorem 43.)

Corollary 10 extends Lebesgue's bounded convergence theorem to continuous functions on a pseudocompact space (i.e., a topological space on which every real continuous function is bounded (and hence attains its bounds)).

Corollary 11 is a strict generalization of the following result of Rainwater: let $\left\{x_{n}\right\}_{n \geqq 1}$ be a bounded sequence in a normed linear space $E, x \in E$ and $\left\langle x_{n}, y\right\rangle \rightarrow\langle x, y\rangle$ for each extreme point $y$ of the unit ball of the dual, $E^{\prime}$, of $E$. Then $x_{n} \rightarrow x$ in $w\left(E, E^{\prime}\right)$. (See [4], p. 33 and [6].)

Corollary 13 is a strict generalization of the following result used in one proof of Krein's Theorem: if $Y$ is a countably compact subset of a real linear topological space, $\left\{f_{n}\right\}_{n \geqq 1}$ is a sequence of continuous linear functionals on $E$ uniformly bounded on $Y$ and $\lim _{n \rightarrow \infty}\left\langle y, f_{n}\right\rangle=0$ whenever $y \in Y$ then $\lim _{n \rightarrow \infty}\left\langle x, f_{n}\right\rangle=0$ whenever $x \in \operatorname{conv}^{-} Y$. (See [2], 17.11, p. 158 and $17 \mathrm{H}$, p. 164.)

All vector spaces considered in this paper will be real.

1. Notation. We suppose that $X \neq \phi$. If $f \in l_{\infty}(X)$ we write $S(f)=\sup f(X), I(f)=\inf f(X)$ and $\|f\|=\sup |f(X)|$. We write "conv" for "convex hull of". 
2. Lemma. We suppose that, for all $n \geqq 1, f_{n} \in l_{\infty}(X)$ and $\sup _{n \geqq 1}\left\|f_{n}\right\|<\infty$. We suppose further that $Y \subset X$ and that, whenever $\lambda_{n} \geqq 0$ and $\sum_{n \geqq 1} \lambda_{n}=1$, there exists $y \in Y$ such that $\sum_{n \geqq 1} \lambda_{n} f_{n}(y)=$ $S\left(\sum_{n \geqq 1} \lambda_{n} f_{n}\right)$.

Then $\sup _{y \in Y} \lim \sup _{n \rightarrow \infty} f_{n}(y) \geqq \inf S\left(\operatorname{conv}\left\{f_{n}: n \geqq 1\right\}\right)$.

Proof. We write $A=\inf S\left(\operatorname{conv}\left\{f_{n}: n \geqq 1\right\}\right)$ and $B=\sup _{n \geqq 1} S\left(f_{n}\right)$. Then $-\infty<A \leqq B<\infty$. We suppose that $\delta>0$ is arbitrary and choose $\lambda>0$ such that $A-\delta(1+\lambda)-B \lambda \geqq(A-2 \delta)(1-\lambda)$ (which implies that $\lambda<1)$. We choose $g_{1}, g_{2}, \ldots$ inductively so that, for all $m \geqq 1, g_{m} \in \operatorname{conv}\left\{f_{n}: n \geqq m\right\}$ and

$$
S\left(\sum_{n \leqq m} \lambda^{n-1} g_{n}\right) \leqq \inf S\left(\sum_{n \leqq m-1} \lambda^{n-1} g_{n}+\lambda^{m-1} \operatorname{conv}\left\{f_{n}: n \geqq m\right\}\right)+\delta\left(\frac{\lambda}{2}\right)^{m} .
$$

Since

$$
\frac{g_{m}+\lambda g_{m+1}}{1+\lambda} \in \operatorname{conv}\left\{f_{n}: n \geqq m\right\}, \quad \text { for all } m \geqq 1
$$

$$
S\left(\sum_{n \leqq m} \lambda^{n-1} g_{n}\right) \leqq S\left(\sum_{n \leqq m-1} \lambda^{n-1} g_{n}+\lambda^{m-1} \frac{g_{m}+\lambda g_{m+1}}{1+\lambda}\right)+\delta\left(\frac{\lambda}{2}\right)^{m} \text {. }
$$

We write $h_{0}=0$, for all $m \geqq 1, h_{m}=\sum_{n \geqq m} \lambda^{n-1} g_{n}$ and $h=\sum_{n \geqq 1} \lambda^{n-1} g_{n}$. Then, multiplying (1) by $(1+\lambda)$, for all $m \geqq 1$

$$
\begin{array}{r}
(1+\lambda) S\left(h_{m}\right) \leqq S\left(\lambda h_{m-1}+h_{m+1}\right)+\delta(1+\lambda)\left(\frac{\lambda}{2}\right)^{m} \\
\leqq \lambda S\left(h_{m-1}\right)+S\left(h_{m+1}\right)+\delta(1+\lambda)\left(\frac{\lambda}{2}\right)^{m}
\end{array}
$$

from which

$$
\frac{S\left(h_{m+1}\right)-S\left(h_{m}\right)}{\lambda^{m}} \geqq \frac{S\left(h_{m}\right)-S\left(h_{m-1}\right)}{\lambda^{m-1}}-\frac{\delta(1+\lambda)}{2^{m}} .
$$

Since $S\left(h_{1}\right)-S\left(h_{0}\right)=S\left(h_{1}\right) \geqq A$, it follows from (2) and induction that, for all $m \geqq 1$,

(3) $\frac{S\left(h_{m}\right)-S\left(h_{m-1}\right)}{\lambda^{m-1}} \geqq A-\delta(1+\lambda)\left(\frac{1}{2}+\frac{1}{4}+\cdots\right)=A-\delta(1+\lambda)$

hence $S(h)-S\left(h_{m-1}\right)=\sum_{n \geqq m}\left[S\left(h_{n}\right)-S\left(h_{n-1}\right)\right] \geqq \sum_{n \geqq m} \lambda^{n-1}[A-\delta(1+\lambda)]$ i.e.

$$
S(h)-S\left(h_{m-1}\right) \geqq \frac{\lambda^{m-1}}{1-\lambda}[A-\delta(1+\lambda)] .
$$

By assumption, there exists $y \in Y$ such that $h(y)=S(h)$. Then for all $m \geqq 1$ 
from (4)

$$
\begin{aligned}
\lambda^{m-1} g_{m}(y) & =h(y)-h_{m-1}(y)-\sum_{n \geqq m+1} \lambda^{n-1} g_{n}(y) \\
& \geqq S(h)-S\left(h_{m-1}\right)-\sum_{n \geqq m+1} \lambda^{n-1} B \\
& \geqq \frac{\lambda^{m-1}}{1-\lambda}[A-\delta(1+\lambda)]-\frac{\lambda^{m}}{1-\lambda} B
\end{aligned}
$$

hence, from the choice of $\lambda, g_{m}(y) \geqq A-2 \delta$. Since $g_{m} \in \operatorname{conv}\left\{f_{n}: n \geqq m\right\}$, for each $m \geqq 1$ there exists $k(m) \geqq m$ such that $f_{k(m)}(y) \geqq A-2 \delta$, from which $\lim \sup _{n \rightarrow \infty} f_{n}(y) \geqq A-2 \delta$. The result follows since $\delta$ is arbitrary.

3. Theorem. If the notation is as in Lemma 2 and $\mu$ is a linear functional on $l_{\infty}(X)$ dominated by $S$ (i.e., a positive linear functional of norm 1) then

$$
\sup _{y \in X} \lim \sup _{n \rightarrow \infty} f_{n}(y) \geqq \lim \sup _{n \rightarrow \infty} \mu\left(f_{n}\right) .
$$

In particular, for all $x \in X$,

$$
\sup _{y \in Y} \lim \sup _{n \rightarrow \infty} f_{n}(y) \geqq \lim \sup _{n \rightarrow \infty} f_{n}(x) .
$$

Proof. If $\sup _{y \in Y} \lim \sup _{n \rightarrow \infty} f_{n}(y)<\lim \sup _{n \rightarrow \infty} \mu\left(f_{n}\right)$ then, by replacing $\left\{f_{n}\right\}$ by an appropriate subsequence, we can assume that

$$
\sup _{y \in Y} \lim \sup _{n \rightarrow \infty} f_{n}(y)<\inf _{n \geqq 1} \mu\left(f_{n}\right) \text {. }
$$

But inf $_{n \geqq 1} \mu\left(f_{n}\right)=\inf \mu\left(\operatorname{conv}\left\{f_{n}: n \geqq 1\right\}\right) \leqq \inf S\left(\operatorname{conv}\left\{f_{n}: n \geqq 1\right\}\right)$ and this would contradict Lemma 2 .

4. Corollary. We suppose that $X$ is a compact convex subset of a real linear topological space $E, Y \subset X$ and

$$
\left\{\begin{array}{l}
\text { whenever } f \text { is a continuous convex function on } X \\
\text { then there exists } y \in Y \text { such that } f(y)=S(f) \text {. }
\end{array}\right.
$$

(a) If, for each $n \geqq 1, f_{n}$ is a continuous convex function on $X, \sup _{n \geqq 1}\left\|f_{n}\right\|<\infty$ and $\lim \sup _{n \rightarrow \infty} f_{n}(y) \leqq 0$ whenever $y \in Y$ then $\lim \sup _{n \rightarrow \infty} f_{n}(x) \leqq 0$ whenever $x \in X$.

(b) If $E$ is locally convex Hausdorff and, for each $n \geqq 1, g_{n}$ is a bounded convex lower semicontinuous function on $X, \sup _{n \geqq 1}\left\|g_{n}\right\|<\infty$ and $\lim \sup _{n \rightarrow \infty} g_{n}(y) \leqq 0$ whenever $y \in Y$ then $\lim \sup _{n \rightarrow \infty} g_{n}(x) \leqq 0$ whenever $x \in X$. In particular, this result is true if $Y=e x X$ (the set of extreme points of $X$ ).

Proof.

(a) is immediate from Theorem 3. 
(b) We suppose $x \in X$. Then, for all $n \geqq 1$, there exists a continuous convex function $f_{n}$ on $X$ such that $I\left(g_{n}\right) \leqq f_{n} \leqq g_{n}$ and $f_{n}(x) \geqq$ $g_{n}(x)-1 / n$. (See [3], p. 222 or [4], p. 19; we can take $f_{n}$ of the form $\max \left\{I\left(g_{n}\right), a_{n}+\left\langle\cdot, x_{n}^{\prime}\right\rangle \mid X\right\}$ where $a_{n} \in R$ and $x_{n} \in E^{\prime}$, the dual of $E$.) The result follows from (a) applied to $\left\{f_{n}: n \geqq 1\right\}$. The final observation follows from Bauer's theorem on extreme points (see [3], p. 225).

5. Example. We write $E$ for the set of all real sequences $\left\{x_{n}\right\}_{n \geqq 0}$ such that $\sum_{n \geqq 0}\left|x_{n}\right|<\infty$ and $E^{\prime}$ for the set of all real sequences $\left\{z_{n}\right\}_{n \geqq 1}$ that are eventually constant. We define $\langle\cdot, \cdot\rangle: E \times E^{\prime} \rightarrow R$ by

$$
\langle x, z\rangle=x_{0} \lim _{n \rightarrow \infty} z_{n}+\sum_{n \geq 1} x_{n} z_{n} .
$$

We write $X=\left\{x: x \in E, \sum_{n \geqq 0}\left|x_{n}\right| \leqq 1\right\}$ and $Y=\left\{ \pm e^{(1)}, \pm e^{(2)}, \cdots\right\} \subset X$. Then $X$ is $w\left(E, E^{\prime}\right)$-compact and

(6) for all $z \in E^{\prime}$ there exists $y \in Y$ such that $\langle y, z\rangle=\sup \langle X, z\rangle$.

If $z_{n} \in E^{\prime}$ is defined by $z_{n, m}=0(m<n)$ and $z_{n, m}=1 \quad(m \geqq n)$ then, for all $y \in Y, \lim _{n \rightarrow \infty}\left\langle y, z_{n}\right\rangle=0$ but $\lim _{n \rightarrow \infty}\left\langle e^{(0)}, z_{n}\right\rangle=1$. So Corollary 4(b) fails if we weaken (5) to (6) even if all the functions $g_{n}$ are in $\left\langle\cdot, E^{\prime}\right\rangle \mid X$.

6. Remark. As is well known, (6) implies that $\bar{Y} \supset e x X$. implies that every $K$-analytic set that contains $Y$ must also contain $X$. (The statement for $K_{o}$ sets follows from Urysohn's Lemma, Corollary 4 , and the fact that if $f_{n} \in C(X)$ and $x \in e x X$ then there exists a continuous affine function $g_{n}$ on $X$ such that $g_{n} \geqq f_{n}$ and $g_{n}(x) \leqq$ $f_{n}(x)+1 / n$. The extension to $K$-analytic sets follows from standard arguments.)

7. Example. We suppose that $\mathscr{A}$ is an uncountable set and we write $E$ for $l_{\infty}(\mathscr{A})$ with the topology $w\left(l_{\infty}(\mathscr{A}), l_{1}(\mathscr{A})\right)$ and $X=$ $\left\{x: x \in E, \sup _{\alpha \in \mathscr{A}}|x(\alpha)| \leqq 1\right\}$. If $f$ is a continuous convex function on $X$ then, from Bauer's Theorem, there exists $x \in e x X$ such that $f(x)=$ $S(f)$. By continuity, there exists $\left\{g_{n}: n \geqq 1\right\} \subset l_{1}(\mathscr{A})$ such that $y \in X$ and $\sup _{n \geqq 1}\left|\left\langle y-x, g_{n}\right\rangle\right|=0$ imply that $f(y)=f(x)=S(f)$. Hence there exists a countable subset $\mathscr{B}$ of $\mathscr{A}$ such that $y \in X$ and $\sup _{\beta \in \infty} \mid y(\beta)-$ $x(\beta) \mid=0$ imply that $f(y)=S(f)$. Consequently, (5) is satisfied if we write $Y=\{y: y \in X$, for all $\alpha \in \mathscr{A}, y(\alpha)=0$ or $\pm 1,\{\alpha: \alpha \in \mathscr{A}, y(\alpha) \neq 0$ is countable\}\}. But $Y \cap e x X=\phi$.

8. THEOREM. We suppose that $\left\{f_{n}: n \geqq 1\right\}$ is as in Lemma 2, $Y \subset X$ and, whenever $\lambda_{n} \geqq 0$ and $\sum_{n \geqq 1} \lambda_{n}=1$, there exist $y, z \in Y$ such that 


$$
\sum_{n \geqq 1} \lambda_{n} f_{n}(y)=S\left(\sum_{n \geqq 1} \lambda_{n} f_{n}\right)
$$

and

$$
\sum_{n \geq 1} \lambda_{n} f_{n}(z)=I\left(\sum_{n \geq 1} \lambda_{n} f_{n}\right)
$$

If $f_{n} \rightarrow 0$ pointwise on $Y$ then $f_{n} \rightarrow 0$ in $w\left(l_{\infty}(X), l_{\infty}(X)^{\prime}\right)$ and, in particular, $f_{n} \rightarrow 0$ pointwise on $X$.

Proof. From Theorem 3, if $\mu$ is a positive linear functional on $l_{\infty}(X)$ then $\lim \sup _{n \rightarrow \infty} \mu\left(f_{n}\right) \leqq 0$. Applying the same argument with $f_{n}$ replaced by $-f_{n}$ we see that $\liminf _{n \rightarrow \infty} \mu\left(f_{n}\right) \geqq 0$. Hence $\lim _{n \rightarrow \infty} \mu\left(f_{n}\right)=$ 0 . The result follows since any element of $l_{\infty}(X)^{\prime}$ is the difference of two positive linear functionals on $l_{\infty}(X)$.

9. Corollary. We suppose that $M$ is a $\|\cdot\|$-closed subspace of $l_{\infty}(X), Y \subset X$ and, for all $f \in M$, there exists $y \in Y$ such that $f(y)=$ $S(f)$. If, for all $n \geqq 1, f_{n} \in M$, $\sup _{n \geqq 1}\left\|f_{n}\right\|<\infty, f \in M$ and $f_{n} \rightarrow f$ pointwise on $Y$ then $f_{n} \rightarrow f$ in $w\left(l_{\infty}(X), l_{\infty}(X)^{\prime}\right)$ and, in particular, $f_{n} \rightarrow f$ pointwise on $X$.

Proof. This is immediate from Theorem 8.

10. Corollary. We suppose that $X$ is a pseudocompact topological space, for all $n \geqq 1 f_{n} \in C(X)$, $\sup _{n \geqq 1}\left\|f_{n}\right\|<\infty, f \in C(X)$ and $f_{n} \rightarrow f$ pointwise on $X$. Then $f_{n} \rightarrow f$ in $w\left(C(X), C(X)^{\prime}\right)$.

Proof. This follows from Corollary 9 with $M=C(X), Y=X$ and the fact (from the Hahn-Banach theorem) that $w\left(l_{\infty}(X), l_{\infty}(X)^{\prime}\right)$ induces $w\left(C(X), C(X)^{\prime}\right)$ on $C(X)$. If we wish to avoid the axiom of choice we can reprove Theorem 3 and Theorem 8 with " $l_{\infty}(X)$ " replaced everywhere by " $C(X)$ " and still obtain the result.

11. Corollary. We suppose that $F$ is a normed linear space with dual $F^{\prime \prime}$ and completion $\widetilde{F}, X$ is the unit ball of $F^{\prime \prime}, Y \subset X$ and for all $x \in \widetilde{F}$ there exists $y \in Y$ such that $\langle x, y\rangle=\|x\|$.

If, for all $n \geqq 1, x_{n} \in F, \sup _{n \geqq 1}\left\|x_{n}\right\|\left\langle\infty, x \in F\right.$ and $\left\langle x_{n}, y\right\rangle \rightarrow\langle x, y\rangle$ for all $y \in Y$ then $x_{n} \rightarrow x$ in $w\left(F, F^{\prime}\right)$. In particular, this result is true if $Y=e x X$.

Proof. The result is immediate from Corollary 9 with $M=$ $\{\langle x, \cdot\rangle \mid X: x \in \widetilde{F}\}$. (We observe that if $x \in \widetilde{F}$ then $\langle x, \cdot\rangle \mid X$ is continuous with respect to the topology induced on $X$ by $w\left(F^{\prime}, F\right)$ although $\langle x, \cdot\rangle$ 
is not necessarily continuous with respect to $w\left(F^{\prime}, F\right)$. So the final comment follows from Bauer's theorem and not the Krein-Milman theorem.)

12. Remark. We can use Example 5 to show that Corollary 11 fails if we weaken (7) to

for all $x \in F$ there exists $y \in Y$ such that $\langle x, y\rangle=\|x\|$.

We can use Example 7 to show that, even though (7) is satisfied, it may happen that $Y \cap e x X=\phi$.

(In the first case we take $F$ to be the $E^{\prime}$ of Example 5 with the supremum norm. Then $F^{\prime \prime}=E$ and $\widetilde{F}=c$. In the second case we take $F$ to be $l_{1}(\mathscr{A})$ with the $l_{1}$ norm. Then $F^{\prime}=l_{\infty}(\mathscr{A})$.)

13. CoRollary. We suppose that $\phi \neq Y \subset E$ and $\left\{f_{n}\right\}_{n \geqq 1}$ is a sequence of real functions on $E$, uniformly bounded on $Y$. We write

$$
\begin{gathered}
X=\left\{x: x \in E, \inf \left(\sum_{n \geqq 1} \lambda_{n} f_{n}\right)(Y) \leqq \sum_{n \geqq 1} \lambda_{n} f_{n}(x) \leqq \sup \left(\sum_{n \geqq 1} \lambda_{n} f_{n}\right)(Y)\right. \text { whenever } \\
\left.\lambda_{n} \geqq 0 \quad(n \geqq 1) \text { and } \sum_{n \geqq 1} \lambda_{n}=1\right\} .
\end{gathered}
$$

If all the functions $\sum_{n \geq 1} \lambda_{n} f_{n}$ attain their infima and suprema on $Y$ and $\lim _{n \rightarrow \infty} f_{n}(y)=0$ whenever $y \in Y$, then $\lim _{n \rightarrow \infty} f_{n}(x)=0$ whenever $x \in X$. If $E$ is a linear topological space and each $f_{n}$ is continuous and affine on $E$ then $X \supset \operatorname{conv}^{-} Y$ and it suffices that $Y$ be pseudocompact.

Proof. This follows immediately from Theorem 8.

\section{REFERENCES}

1. R. C. James, Weakly compact sets, Trans. Amer. Math. Soc., 13 (1964), 129-140.

2. J. L. Kelley and I. Namioka, Linear Topological Spaces, Van Nostrand, 1963.

3. P. A. Meyer, Theory of Probability, Blasisdell, New York, 1965.

4. R. R. Phelps, Lectures on Choquet's Theorem, Van Nostrand Mathematical Studies \#7, 1966.

5. J. D. Pryce, Weak compactness in locally convex spaces, Proc. Amer. Math. Soc., 17 (1966), 148-155.

6. J. Rainwater, Weak convergence of bounded sequences, Proc. Amer. Math. Soc., 14 (1963), 999.

7. S. Simons, Minimal sublinear functionals, Studia Math., 37 (1970), 37-56.

Received January 28, 1971. This research was supported in part by NSF grant number 20632. 


\section{PACIFIC JOURNAL OF MATHEMATICS}

\section{EDITORS}

\section{H. SAMELSON}

Stanford University

Stanford, California 94305

\section{R. HOBBY}

University of Washington Seattle, Washington 98105

\section{J. DugundJI}

Department of Mathematics University of Southern California Los Angeles, California 90007

RICHARD ARENS

University of California Los Angeles, California 90024

\section{ASSOCIATE EDITORS}
E. F. BECKENBACH
B. H. Neumann
F. WoLF
K. YoSHIDA

\section{SUPPORTING INSTITUTIONS}

UNIVERSITY OF BRITISH COLUMBIA CALIFORNIA INSTITUTE OF TECHNOLOGY

UNIVERSITY OF CALIFORNIA

MONTANA STATE UNIVERSITY

UNIVERSITY OF NEVADA

NEW MEXICO STATE UNIVERSITY

OREGON STATE UNIVERSITY

UNIVERSITY OF OREGON

OSAKA UNIVERSITY

\author{
UNIVERSITY OF SOUTHERN CALIFORNIA \\ STANFORD UNIVERSITY \\ UNIVERSITY OF TOKYO \\ UNIVERSITY OF UTAH \\ WASHINGTON STATE UNIVERSITY \\ UNIVERSITY OF WASHINGTON \\ * * * * \\ AMERICAN MATHEMATICAL SOCIETY \\ NAVAL WEAPONS CENTER
}

The Supporting Institutions listed above contribute to the cost of publication of this Journal, but they are not owners or publishers and have no responsibility for its content or policies.

Mathematical papers intended for publication in the Pacific Journal of Mathematics should be in typed form or offset-reproduced, (not dittoed), double spaced with large margins. Underline Greek letters in red, German in green, and script in blue. The first paragraph or two must be capable of being used separately as a synopsis of the entire paper. The editorial "we" must not be used in the synopsis, and items of the bibliography should not be cited there unless absolutely necessary, in which case they must be identified by author and Journal, rather than by item number. Manuscripts, in duplicate if possible, may be sent to any one of the four editors. Please classify according to the scheme of Math. Rev. Index. to Vol. 39. All other communications to the editors should be addressed to the managing editor, Richard Arens, University of California, Los Angeles, California, 90024.

50 reprints are provided free for each article; additional copies may be obtained at cost in multiples of 50 .

The Pacific Journal of Mathematics is published monthly. Effective with Volume 16 the price per volume (3 numbers) is $\$ 8.00$; single issues, $\$ 3.00$. Special price for current issues to individual faculty members of supporting institutions and to individual members of the American Mathematical Society: $\$ 4.00$ per volume; single issues $\$ 1.50$. Back numbers are available.

Subscriptions, orders for back numbers, and changes of address should be sent to Pacific Journal of Mathematics, 103 Highland Boulevard, Berkeley, California, 94708.

PUBLISHED BY PACIFIC JOURNAL OF MATHEMATICS, A NON-PROFIT CORPORATION

Printed at Kokusai Bunken Insatsusha (International Academic Printing Co., Ltd.), 270, 3-chome Totsuka-cho, Shinjuku-ku, Tokyo 160, Japan. 


\section{Pacific Journal of Mathematics}

\section{Vol. 40, No. $3 \quad$ November, 1972}

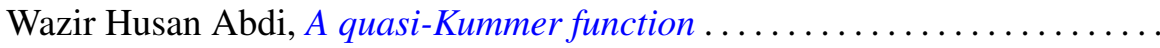

Vasily Cateforis, Minimal injective cogenerators for the class of modules of

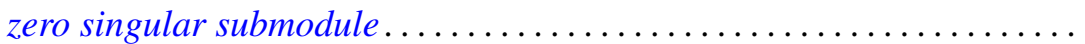

W. Wistar (William) Comfort and Anthony Wood Hager, Cardinality of

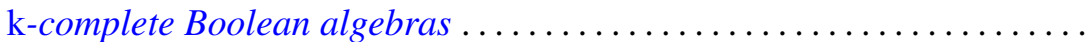

Richard Brian Darst and Gene Allen DeBoth, Norm convergence of martingales of Radon-Nikodym derivatives given a $\sigma$-lattice ..........

M. Edelstein and Anthony Charles Thompson, Some results on nearest points and support properties of convex sets in $c_{0} \ldots \ldots \ldots \ldots \ldots$

Richard Goodrick, Two bridge knots are alternating knots .

Jean-Pierre Gossez and Enrique José Lami Dozo, Some geometric properties related to the fixed point theory for nonexpansive mappings ..........

Dang Xuan Hong, Covering relations among lattice varieties .............

Carl Groos Jockusch, Jr. and Robert Irving Soare, Degrees of members of $\Pi_{1}^{0}$

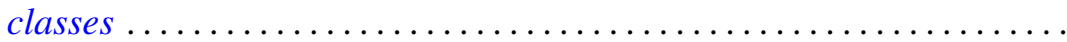

565

575

605

Leroy Milton Kelly and R. Rottenberg, Simple points in pseudoline

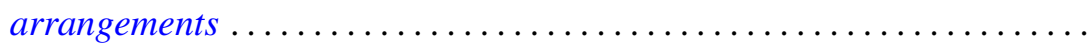

Joe Eckley Kirk, Jr., The uniformizing function for a class of Riemann surfaces....

Glenn Richard Luecke, Operators satisfying condition $\left(G_{1}\right)$ locally ... 629

T. S. Motzkin, On L $(S)$-tuples and l-pairs of matrices ... . .

Charles Estep Murley, The classification of certain classes of torsion free

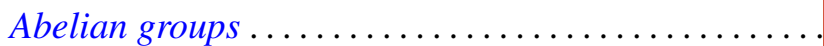

Louis D. Nel, Lattices of lower semi-continuous functions and associated topological spaces.

David Emroy Penney, II, Establishing isomorphism between tame prime

knots in $E^{3}$. . .

Daniel Rider, Functions which operate on $\mathscr{F} L_{p}(T), 1<p<2$

Thomas Stephen Shores, Injective modules over duo rings ...

Stephen Simons, A convergence theorem with boundary. .

703

Stephen Simons, Maximinimax, minimax, and antiminimax theorems and a

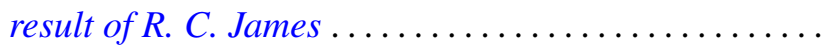

Stephen Simons, On Ptak's combinatorial lemma ........

Stuart A. Steinberg, Finitely-valued $f$-modules............

Pui-kei Wong, Integral inequalities of Wirtinger-type and fourth-order

elliptic differential inequalities .

Yen-Yi Wu, Completions of Boolean algebras with partially additive

operators ..................................

Phillip Lee Zenor, On spaces with regular $G_{\delta}$-diagonals . . . 